\title{
Adomian Decomposition Method with Modified Bernstein Polynomials for Solving Ordinary and Partial Differential Equations
}

\author{
Ahmed Farooq Qasim (D) and Ekhlass S. AL-Rawi \\ College of Computer Sciences and Mathematics, University of Mosul, Iraq \\ Correspondence should be addressed to Ahmed Farooq Qasim; ahmednumerical@yahoo.com
}

Received 7 July 2018; Accepted 24 September 2018; Published 11 October 2018

Academic Editor: Jafar Biazar

Copyright (C) 2018 Ahmed Farooq Qasim and Ekhlass S. AL-Rawi. This is an open access article distributed under the Creative Commons Attribution License, which permits unrestricted use, distribution, and reproduction in any medium, provided the original work is properly cited.

\begin{abstract}
In this paper, we used Bernstein polynomials to modify the Adomian decomposition method which can be used to solve linear and nonlinear equations. This scheme is tested for four examples from ordinary and partial differential equations; furthermore, the obtained results demonstrate reliability and activity of the proposed technique. This strategy gives a precise and productive system in comparison with other traditional techniques and the arrangements methodology is extremely straightforward and few emphasis prompts high exact solution. The numerical outcomes showed that the acquired estimated solutions were in appropriate concurrence with the correct solution.
\end{abstract}

\section{Introduction}

Adomian decomposition technique was established by George Adomian and has as of late turned into an extremely recognized strategy in connected sciences. The technique does not require any diminutiveness presumptions or linearization to solve the ordinary and partial differential equations and this produces the strategy extremely effective among alternate strategies. Recently, many iteration techniques have been used for solving nonlinear equations from ordinary, partial, and fractional equations [1], like variational iteration method and differential transform method [2], homotopy perturbation, and analysis methods [3]. Numerous works have been tested in various different regions, for example, warmth or mass exchange, incompressible fluid, nonlinear optics and gas elements wonders $[4,5]$, fractional Maxwell fluid $[6,7]$, and the Oldroyd-B fluid model [8].

The approximation used polynomials extremely important in scientific experiments where many rely on topics such as the study of statistics different population and the temperatures and others on the approximation theory. In addition, many experiments rely mainly on the approximate measurements and observations to be studied and processed by the appropriate scientific methods in order to reach the results expected from the study.

The Adomian decomposition technique is improved via Chebyshev polynomials in $[9,10]$, with Legendre polynomials [11] and with Laguerre polynomials [12].

This paper is organized as follows. In Section 2, the basic ideas of the modified Bernstein polynomials are described. Section 3 is devoted to solving a nonlinear differential equations using Adomian decomposition method based on modified Bernstein polynomials, the results and comparisons of the numerical solutions are presented in Section 4, and concluding remarks are given in Section 5.

\section{The Modified Bernstein Polynomials}

Polynomials are the mathematical technique as these can be characterized, figured, separated, and incorporated effortlessly. The Bernstein premise polynomials are trying to inexact the capacities. Bernstein polynomials are the better guess to a capacity with a couple of terms. These polynomials are utilized as a part of the fields of connected arithmetic and material science and PC helped geometric outlines and are likewise joined with different techniques like Galerkin and 
collocation technique to solve some differential and integral equations [13].

Definition 1 (Bernstein basis polynomials). The Bernstein basis polynomials of degree $\mathrm{m}$ over the interval $[0,1]$ are defined by

$$
B_{i, m}(x)=\left(\begin{array}{c}
m \\
i
\end{array}\right) x^{i}(1-x)^{m-i}
$$

where the binomial coefficient is

$$
\left(\begin{array}{c}
m \\
i
\end{array}\right)=\frac{m !}{i !(m-i) !}
$$

For example, when $m=5$, then the Bernstein terms are

$$
\begin{aligned}
& B_{0,5}(x)=(1-x)^{5} \\
& B_{1,5}(x)=5 x(1-x)^{4} \\
& B_{2,5}(x)=10 x^{2}(1-x)^{3} \\
& B_{3,5}(x)=10 x^{3}(1-x)^{2} \\
& B_{4,5}(x)=5 x^{4}(1-x) \\
& B_{5,5}(x)=x^{5}
\end{aligned}
$$

Definition 2 (Bernstein polynomials). A linear combination of Bernstein basis polynomials

$$
B_{m}(x)=\sum_{i=0}^{m} B_{i, m}(x) \beta_{i}
$$

is called the Bernstein polynomials of degree $\mathrm{m}$, where $\beta_{i}$ are the Bernstein coefficients.

Definition 3. Let $f$ be a real valued function defined and bounded on $[0,1]$; let $B_{m}(f)$ be the polynomial on $[0,1]$, defined by

$$
B_{m}(f)=\sum_{i=0}^{m}\left(\begin{array}{c}
m \\
i
\end{array}\right) x^{i}(1-x)^{m-i} f\left(\frac{i}{m}\right)
$$

where $B_{m}(f)$ is the m-th Bernstein polynomials for $f(x)$.

For each function $f:[0,1] \longrightarrow R$, we have

$$
\lim _{m \longrightarrow \infty} B_{m}^{f}(x)=f(x)
$$

Example. If $f(x)=e^{x}, x \in[0,1]$ then the Bernstein expanded for the function $f(x)$ when $\mathrm{m}=5$ is

$$
\begin{aligned}
B_{m}(f)= & f(0)(1-x)^{5}+f\left(\frac{1}{5}\right) 5 x(1-x)^{4} \\
& +f\left(\frac{2}{5}\right) 10 x^{2}(1-x)^{3} \\
& +f\left(\frac{3}{5}\right) 10 x^{3}(1-x)^{2} \\
& +f\left(\frac{4}{5}\right) 5 x^{4}(1-x)+f(1) x^{5}
\end{aligned}
$$

$$
\begin{aligned}
B_{m}(f)= & e^{0}(1-x)^{5}+5 e^{1 / 5} x(1-x)^{4} \\
& +10 e^{2 / 5} x^{2}(1-x)^{3}+10 e^{3 / 5} x^{3}(1-x)^{2} \\
& +5 e^{4 / 5} x^{4}(1-x)+e^{1} x^{5}
\end{aligned}
$$

In (1986) [14] Lorentz, prove that if the $2 k$-th order derivative $f^{2 k}(x)$ is bounded in the interval $(0,1)$ then for each $x \in[0,1]$

$$
B_{m}^{f}(x)=f(x)+\sum_{a=2}^{2 k-1} \frac{f^{(a)}(x)}{a ! m^{a}} T_{m, a}(x)+O\left(\frac{1}{m^{k}}\right)
$$

where

$$
T_{m, a}(x)=\sum_{k}(k-m x)^{a}\left(\begin{array}{l}
m \\
k
\end{array}\right) x^{k}(1-x)^{m-k}
$$

Remark (see [15]). Notice that $T_{m, a}(x)$ is the $a$-th central moment of a random variable with a binomial appropriation with parameters $m$ and $x$. Clearly, $T_{m, 0}=1, T_{m, 1}=0$. It is well known that the sequence $\left\{T_{m, a}(x)\right\}$ satisfies the following recurrence:

$$
T_{m, a+1}(x)=x(1-x)\left(T_{m, a}^{\prime}(x)+m a T_{m, a-1}(x)\right)
$$

If we apply (8) to $k=1 ; 2 ; 3$, then we obtain

$$
\begin{aligned}
& B_{m}^{f}(x)=f(x)+O\left(\frac{1}{m}\right) \\
& B_{m}^{f}(x)=f(x)+\frac{x(1-x) f^{\prime \prime}(x)}{2 m}+O\left(\frac{1}{m^{2}}\right) \\
& B_{m}^{f}(x)=f(x)+\frac{x(1-x) f^{\prime \prime}(x)}{2 m} \\
&+ \frac{x(1-x)\left(4(1-2 x) f^{(3)}(x)+3 x(1-x) f^{(4)}(x)\right)}{24 m^{2}} \\
&+O\left(\frac{1}{m^{3}}\right)
\end{aligned}
$$

and higher level approximations can be computed.

\section{ADM Based on Modified Bernstein Polynomials}

Let us consider the following equation:

$$
L u+N u+R u=g(x)
$$

where $L$ is an invertible linear term, $N$ represents the nonlinear term, and $R$ is the remaining linear part; from (12) we have

$$
L u=g(x)-N u-R u .
$$

Now, applying the inverse factor $L^{-1}$ to both sides of (13) then via the initial conditions we find

$$
u=f(x)-L^{-1} N u-L^{-1} R u,
$$


where $L^{-1}=\int_{0}^{x}() d$.$s and f(x)$ are the terms having from integrating the rest of the term $g(x)$ and from utilizing the given initial or boundary conditions. The ADM assumes that $N(u)$ (nonlinear term) can be decomposed by an infinite series of polynomials which is expressed in form

$$
N(u)=\sum_{n=0}^{\infty} A_{n}\left(u_{o}, u_{1}, \ldots, u_{n}\right)
$$

where $A_{\mathrm{n}}$ are the Adomian's polynomials [16] defined as

$$
A_{n}=\frac{1}{n !} \frac{d^{n}}{d \lambda^{\mathrm{n}}}\left[N\left(\sum_{i=0}^{\infty} \lambda^{\mathrm{i}} \mathrm{u}_{\mathrm{i}}\right)\right]_{\lambda=0}, \mathrm{n}=0,1,2, \ldots
$$

We expand the function $g(x)$ by Bernstein series

$$
g(x)=\sum_{i=0}^{m} a_{i} B_{i}(x)
$$

where $B_{i}(x)$ is the Bernstein polynomials.

Now, using (14) and (17) we have

$$
\begin{aligned}
u_{0} & =L^{-1}\left(a_{0} B_{0}(x)+a_{1} B_{1}(x)+a_{2} B_{2}(x)\right. \\
& \left.+\cdots \cdot a_{m} B_{m}(x)\right)+\theta(x), \\
u_{1} & =-L^{-1}\left(R u_{0}\right)-L^{-1}\left(N u_{0}\right), \\
u_{2} & =-L^{-1}\left(R u_{1}\right)-L^{-1}\left(N u_{1}\right),
\end{aligned}
$$

and so on. These formulas are easy to compute by using Maple 13 software.

In this paper, we improve the function $g(x)$ using modified Bernstein series

$$
\begin{aligned}
g(x)= & \sum_{i=0}^{m}\left(\begin{array}{c}
m \\
i
\end{array}\right) x^{i}(1-x)^{m-i} f\left(\frac{i}{m}\right) \\
& -\sum_{a=2}^{2 k-1} \frac{f^{(a)}(x)}{a ! m^{a}} T_{m, a}(x)
\end{aligned}
$$

And we can approach the derivatives using the Bernstein polynomials

$$
\frac{d}{d x} B_{i, m}(x)=m\left(B_{i-1, m-1}(x)-B_{i, m-1}(x)\right),
$$

Then (19) becomes

$$
\begin{aligned}
g(x)= & \sum_{i=0}^{m}\left(\begin{array}{c}
m \\
i
\end{array}\right) x^{i}(1-x)^{m-i} f\left(\frac{i}{m}\right) \\
& -\sum_{a=2}^{2 k-1} \frac{\left(d^{(a)} / d x^{(a)}\right) B_{i, m}(x)}{a ! m^{a}} T_{m, a}(x)
\end{aligned}
$$

Now, using (18) and (21) we have

$$
\begin{gathered}
u_{0}=L^{-1}\left(B_{i, m}(x)\right)+\theta(x), \\
u_{1}=-L^{-1}\left(R u_{0}\right)-L^{-1}\left(N u_{0}\right), \\
u_{2}=-L^{-1}\left(R u_{1}\right)-L^{-1}\left(N u_{1}\right),
\end{gathered}
$$

The above equation is governing equation of ADM using modified Bernstein polynomials. The obtained approximate solution, $\omega_{V}(x)=\sum_{i=0}^{V} u_{i}$, by (22) has a comparison with the classic approximation solution and the correct solution.

\section{Numerical Results}

In this section, we solve ordinary and partial differential equations by ADM based on Bernstein polynomials and we compare with ADM based on classical Bernstein polynomial.

Example 1. Consider the ordinary equation

$$
\begin{aligned}
\frac{d^{2} y}{d t^{2}}+t \frac{d y}{d t}+t^{2} y^{3} & =\left(2+6 t^{2}\right) e^{t^{2}}+t^{2} e^{3 t^{2}} \\
y(0) & =1 \\
\frac{d y}{d t}(0) & =0
\end{aligned}
$$

with the exact solution $(t)=e^{t^{2}}$. Using (12) we have

$$
L y+N y+R y=g(x)
$$

where $L=d^{2} / d t^{2}, R y=t(d / d t), N y=t^{2} y^{3}$, and $g(t)=(2+$ $\left.6 t^{2}\right) e^{t^{2}}+t^{2} e^{3 t^{2}}$.

The Adomian polynomials for representing the nonlinear term Ny are

$$
\begin{gathered}
A_{0}=t^{2} y_{0}^{3}, \\
A_{1}=t^{2}\left(3 y_{0}^{2} y_{1}\right), \\
A_{2}=t^{2}\left(3 y_{0}^{2} y_{2}+3 y_{0} y_{1}^{2}\right),
\end{gathered}
$$

Now $L^{-1}=\int_{0}^{t} \int_{0}^{t}() d t d$.$t ; then using (5) the classical Bernstein$ polynomials of $g(t)$ when $\mathrm{v}=\mathrm{m}=6$ are

$$
\begin{aligned}
g_{b}(t)= & 2+1.547324 t+9.290164 t^{2}+7.83289 t^{3} \\
& +9.751887 t^{4}+7.659668 t^{5}+3.749864 t^{6}
\end{aligned}
$$

And modified Bernstein polynomials (21) of $g(t)$ with $\mathrm{k}=2$ are

$$
\begin{aligned}
g_{m b}(t)= & 2-0.001037 t+6.922082 t^{2}+1.997441 t^{3} \\
& +6.737662 t^{4}+11.051121 t^{5}+13.124523 t^{6}
\end{aligned}
$$


TABLE 1: Comparison of absolute errors using $y_{6}$ when $\mathrm{m}=\mathrm{v}=6$ and $\mathrm{k}=2$.

\begin{tabular}{llr}
\hline$t$ & $\left|y_{\text {exact }}-y_{b}\right|$ & $\left|y_{\text {exact }}-y_{\text {mb }}\right|$ \\
\hline 0 & 0 & 0 \\
\hline 0.01 & $2.580000 \mathrm{E}-7$ & $2.000000 \mathrm{E}-9$ \\
\hline 0.02 & $2.068000 \mathrm{E}-6$ & $2.900000 \mathrm{E}-8$ \\
\hline 0.03 & $6.992000 \mathrm{E}-6$ & $1.420000 \mathrm{E}-7$ \\
\hline 0.04 & $1.660300 \mathrm{E}-5$ & $4.450000 \mathrm{E}-7$ \\
\hline 0.05 & $3.249600 \mathrm{E}-5$ & $1.074000 \mathrm{E}-6$ \\
\hline 0.06 & $5.629000 \mathrm{E}-5$ & $2.207000 \mathrm{E}-6$ \\
\hline 0.07 & $8.962800 \mathrm{E}-5$ & $4.057000 \mathrm{E}-6$ \\
\hline 0.08 & $1.341850 \mathrm{E}-4$ & $6.872000 \mathrm{E}-6$ \\
\hline 0.09 & $1.916690 \mathrm{E}-4$ & $1.093000 \mathrm{E}-5$ \\
\hline 0.1 & $2.638350 \mathrm{E}-4$ & $1.654900 \mathrm{E}-5$ \\
\hline MSE & $1.369383957 \mathrm{E}-8$ & $4.632475500 \mathrm{E}-11$ \\
\hline
\end{tabular}

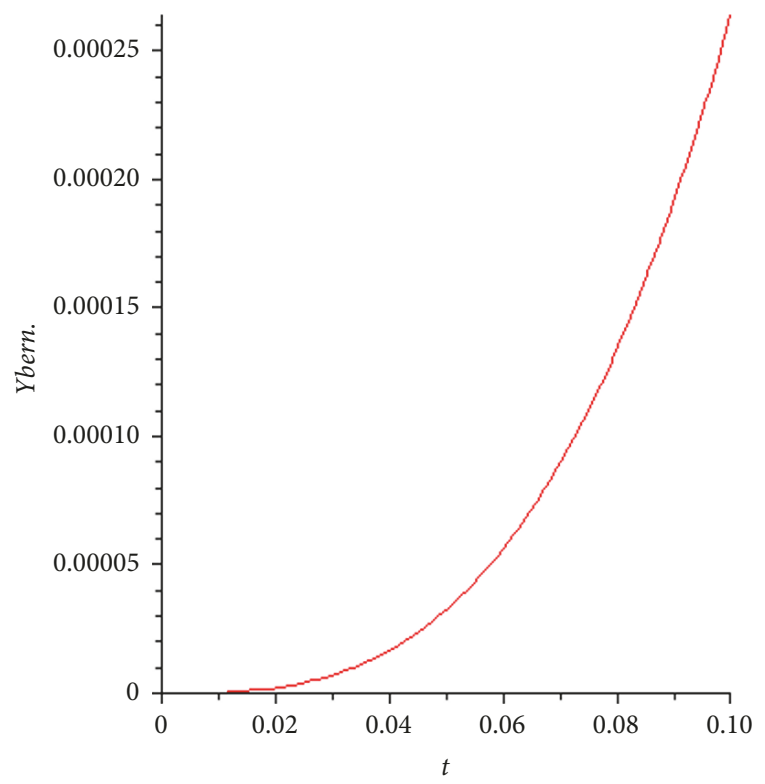

(a)

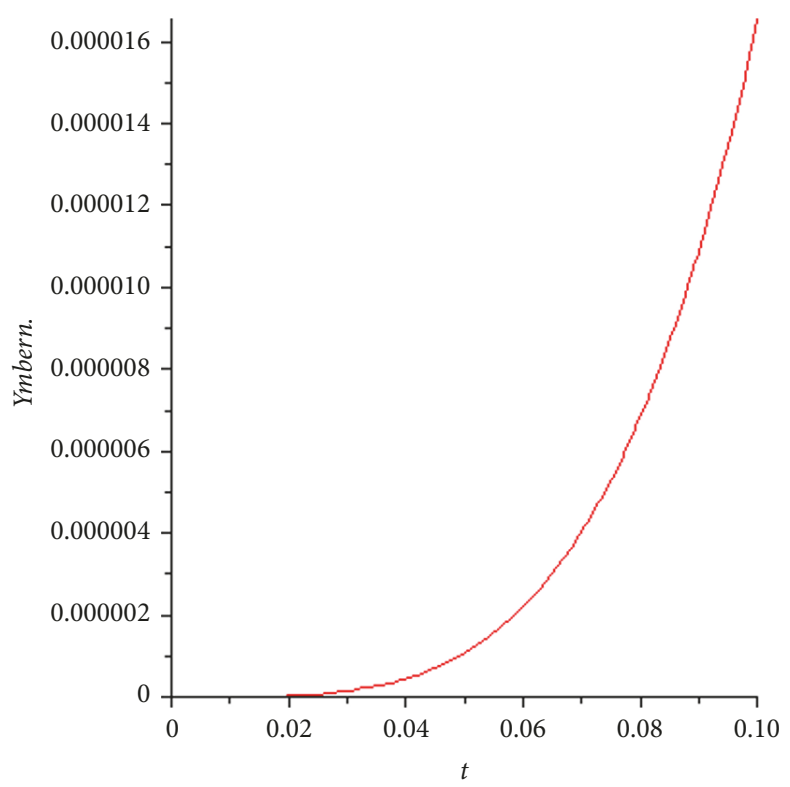

(b)

FIgURE 1: The absolute error between ADM with modified Bernstein polynomials and the exact solution when $\mathrm{m}=\mathrm{v}=6 \mathrm{and} \mathrm{k}=2$.

By (22), we have

$$
\begin{aligned}
y_{0} & =L^{-1}\left(g_{m b}(t)\right)+y(0)+\frac{d y}{d t}(0) t=1+t^{2} \\
& -0.000173 t^{3}+0.57684 t^{4}+0.099872 t^{5} \\
& +0.224589 t^{6}+0.263122 t^{7}+0.234367 t^{8}, \\
y_{1} & =-L^{-1}\left(t \frac{d}{d t} y_{0}\right)-L^{-1}\left(A_{0}\right)=-0.25 t^{4} \\
& +0.000026 t^{5}-0.176912 t^{6}-0.011877 t^{7}+\cdots, \\
y_{2} & =-L^{-1}\left(t \frac{d}{d t} y_{1}\right)-L^{-1}\left(A_{1}\right)=0.033333 t^{6}
\end{aligned}
$$

$$
-0.000003 t^{7}+0.032348 t^{8}+0.011536 t^{9}+\cdots,
$$

And we obtain

$$
\begin{aligned}
y_{m b}(t) & =\sum_{i=0}^{6} y_{i} \\
& =1+t^{2}-0.000173 t^{3}+0.32684 t^{4}+\cdots .
\end{aligned}
$$

The absolute error of $y_{m b}(t)$ and $y_{b}(t)$ is presented in Table 1 and Figure 1.

Figure 1 presents the absolute error of ADM with Bernstein polynomial in (a) and ADM with modified Bernstein 
TABLE 2: Comparison of absolute errors using $y_{10}$ when $\mathrm{m}=16, \mathrm{v}=4$, and $\mathrm{k}=2$.

\begin{tabular}{llr}
\hline$t$ & $\left|y_{\text {exact }}-y_{b}\right|$ & $\left|y_{\text {exact }}-y_{\text {mb }}\right|$ \\
\hline 0 & 0 & 0 \\
\hline 0.1 & $2.061126 \mathrm{E}-6$ & $3.074560 \mathrm{E}-7$ \\
\hline 0.2 & $1.145239 \mathrm{E}-5$ & $1.058636 \mathrm{E}-5$ \\
\hline 0.3 & $1.315732 \mathrm{E}-5$ & $5.114716 \mathrm{E}-5$ \\
\hline 0.4 & $2.165603 \mathrm{E}-4$ & $1.331415 \mathrm{E}-4$ \\
\hline 0.5 & $8.646500 \mathrm{E}-4$ & $2.420463 \mathrm{E}-4$ \\
\hline 0.6 & $2.311555 \mathrm{E}-3$ & $3.299021 \mathrm{E}-4$ \\
\hline 0.7 & $4.905204 \mathrm{E}-3$ & $3.231831 \mathrm{E}-4$ \\
\hline 0.8 & $8.829753 \mathrm{E}-3$ & $1.540876 \mathrm{E}-4$ \\
\hline 0.9 & $1.391114 \mathrm{E}-2$ & $1.870564 \mathrm{E}-4$ \\
\hline 1 & $1.946226 \mathrm{E}-2$ & $6.088701 \mathrm{E}-4$ \\
\hline MSE & $6.804632 \mathrm{E}-5$ & $7.217798344 \mathrm{E}-8$ \\
\hline
\end{tabular}

polynomial in (b) at $\mathrm{m}=\mathrm{v}=6$ and $\mathrm{k}=2$. The absolute errors generated using the ADM with Bernstein polynomial are of $10^{-4}$ while the errors yielded from ADM with modified Bernstein polynomial are of $10^{-5}$.

Example 2. Consider the ordinary equation

$$
\begin{aligned}
\frac{d^{2} y}{d t^{2}}+y \frac{d y}{d t} & =t \sin \left(2 t^{2}\right)-4 t^{2} \sin \left(t^{2}\right)+2 \cos \left(t^{2}\right), \\
y(0) & =0 \\
\frac{d y}{d t}(0) & =0
\end{aligned}
$$

with the exact solution $(t)=\sin \left(t^{2}\right)$.

Here, $L=d^{2} / d t^{2}, N y=y(d y / d t)$, and $g(t)=t \sin \left(2 t^{2}\right)-$ $4 t^{2} \sin \left(t^{2}\right)+2 \cos \left(t^{2}\right)$.

The Adomian polynomials for represent the nonlinear term $\mathrm{Nu}$ are

$$
\begin{gathered}
A_{0}=y_{0} \frac{d}{d t} y_{0}, \\
A_{1}=y_{1} \frac{d}{d t} y_{0}+y_{0} \frac{d}{d t} y_{1}, \\
A_{2}=y_{2} \frac{d}{d t} y_{0}+y_{1} \frac{d}{d t} y_{1}+y_{0} \frac{d}{d t} y_{1},
\end{gathered}
$$

Then using (5) the classical Bernstein polynomials of $g(t)$ when $\mathrm{v}=4$ and $\mathrm{m}=16$ is

$$
\begin{aligned}
g_{b}(t)= & 20.00659171 t+0.2233190 t^{2}+0.098085 t^{3} \\
& -3.39540 t^{4}+\cdots
\end{aligned}
$$

And modified Bernstein polynomials (21) of $\mathrm{g}(\mathrm{t})$ with $\mathrm{k}=2$ are

$$
\begin{aligned}
g_{m b}(t)= & 2-0.007366 t+0.2188855 t^{2}+1.389751 t^{3} \\
& -4.50213 t^{4}+\cdots
\end{aligned}
$$

By (22), we have

$$
\begin{aligned}
y_{m b}(t)= & \sum_{i=0}^{4} y_{i} \\
= & t^{2}-0.001228 t^{3}+0.018241 t^{4}-0.030513 t^{5} \\
& +\cdots
\end{aligned}
$$

The absolute error of $y_{m b}(t)$ and $y_{b}(t)$ is presented in Table 2 and Figure 2.

Figure 2 presents the absolute error of ADM with Bernstein polynomial in (a) and ADM with modified Bernstein polynomial in (b) at $\mathrm{m}=\mathrm{v}=10$ and $\mathrm{k}=3$. The absolute errors generated using the ADM with Bernstein polynomial are of $10^{-2}$ while the errors yielded from ADM with modified Bernstein polynomial are of $10^{-4}$.

Example 3. Consider the ordinary equation

$$
\begin{aligned}
\frac{d y}{d t}-t y+y^{2} & =e^{t^{2}} \\
y(0) & =1,
\end{aligned}
$$

with the exact solution $(t)=e^{t^{2} / 2}$.

Here $L=d / d t, R u=-t y, N y=y^{2}$, and $g(t)=e^{t^{2}}$.

Then using (5) the classical Bernstein polynomials of $g(t)$ when $\mathrm{v}=8$ and $\mathrm{m}=12$ is

$$
\begin{aligned}
g_{b}(t)= & +0.083623 t+0.939177 t^{2}+0.197729 t^{3} \\
& +0.331572 t^{4}+\cdots,
\end{aligned}
$$


TABLE 3: Comparison of absolute errors using $y_{10}$ when $\mathrm{m}=12$, $\mathrm{v}=8$, and $\mathrm{k}=3$.

\begin{tabular}{llr}
\hline$t$ & $\left|y_{\text {exact }}-y_{b}\right|$ & $\left|y_{\text {exact }}-y_{\text {mb }}\right|$ \\
\hline 0 & 0 & 0 \\
\hline 0.01 & $4.134000 \mathrm{E}-6$ & $1.750000 \mathrm{E}-7$ \\
\hline 0.02 & $1.635300 \mathrm{E}-5$ & $6.400000 \mathrm{E}-7$ \\
\hline 0.03 & $3.639700 \mathrm{E}-5$ & $1.314000 \mathrm{E}-6$ \\
\hline 0.04 & $6.402400 \mathrm{E}-5$ & $2.123000 \mathrm{E}-6$ \\
\hline 0.05 & $9.900900 \mathrm{E}-5$ & $2.999000 \mathrm{E}-6$ \\
\hline 0.06 & $1.411460 \mathrm{E}-4$ & $3.883000 \mathrm{E}-6$ \\
\hline 0.07 & $1.902410 \mathrm{E}-4$ & $4.720000 \mathrm{E}-6$ \\
\hline 0.08 & $2.461180 \mathrm{E}-4$ & $5.463000 \mathrm{E}-6$ \\
\hline 0.09 & $3.086100 \mathrm{E}-4$ & $6.069000 \mathrm{E}-6$ \\
\hline 0.1 & $3.775690 \mathrm{E}-4$ & $6.501000 \mathrm{E}-6$ \\
\hline MSE & $3.699974901 \mathrm{E}-8$ & $1.619641710 \mathrm{E}-11$ \\
\hline
\end{tabular}

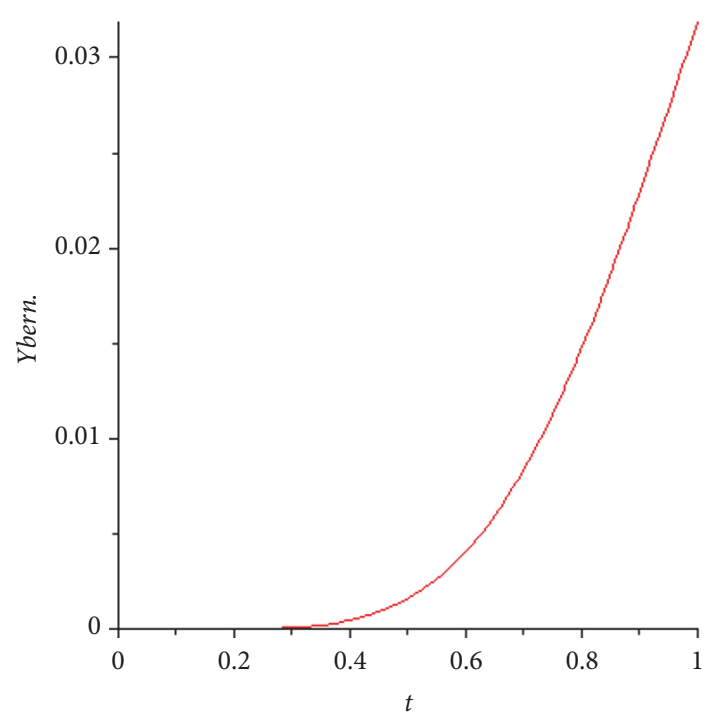

(a)

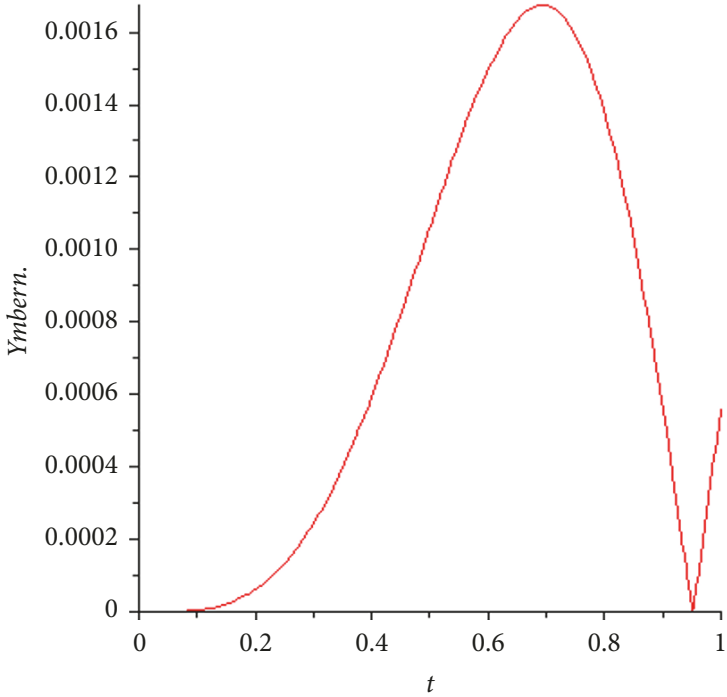

(b)

FIGURE 2: The absolute error between ADM with modified Bernstein polynomials and the exact solution when $\mathrm{m}=\mathrm{v}=10$ and $\mathrm{k}=3$.

and modified Bernstein polynomials (21) of $g(t)$ with $\mathrm{k}=3$ are

$$
\begin{aligned}
g_{m b}(t)= & 1+0.003794 t+0.957094 t^{2}+0.103509 t^{3} \\
& +0.410289 t^{4}+\cdots .
\end{aligned}
$$

By (22), we have

$$
\begin{aligned}
u_{m b}(t)= & \sum_{i=0}^{8} u_{i} \\
= & 1+0.501897 t^{2}-0.015567 t^{3}+0.159135 t^{4} \\
& +\cdots
\end{aligned}
$$

The absolute error of $u_{m b}(t)$ and $u_{b}(t)$ is presented in Table 3 and Figure 3.

Figure 3 presents the absolute error of ADM with Bernstein polynomial in (a) and ADM with modified Bernstein polynomial in (b) at $\mathrm{m}=12, \mathrm{v}=8$, and $\mathrm{k}=3$. The absolute errors generated using the $\mathrm{ADM}$ with Bernstein polynomial are of $10^{-4}$ while the errors yielded from ADM with modified Bernstein polynomial are of $10^{-6}$.

Example 4. Consider the partial differential equation

$$
\begin{aligned}
\frac{\partial y}{\partial t}+y \frac{\partial y}{\partial x}-v \frac{\partial^{2} y}{\partial x^{2}} & =x\left(2 t \cos \left(t^{2}\right)+\sin ^{2}\left(t^{2}\right)\right) \\
y(x, 0) & =0
\end{aligned}
$$

Using (12) we have

$$
L y+N y+R y=g(x, t)
$$

where $L=d / d t, R y=-v\left(\partial^{2} y / \partial x^{2}\right), N y=y(\partial y / \partial x)$, and $g(x, t)=x\left(2 t \cos \left(t^{2}\right)+\sin ^{2}\left(t^{2}\right)\right)$. 


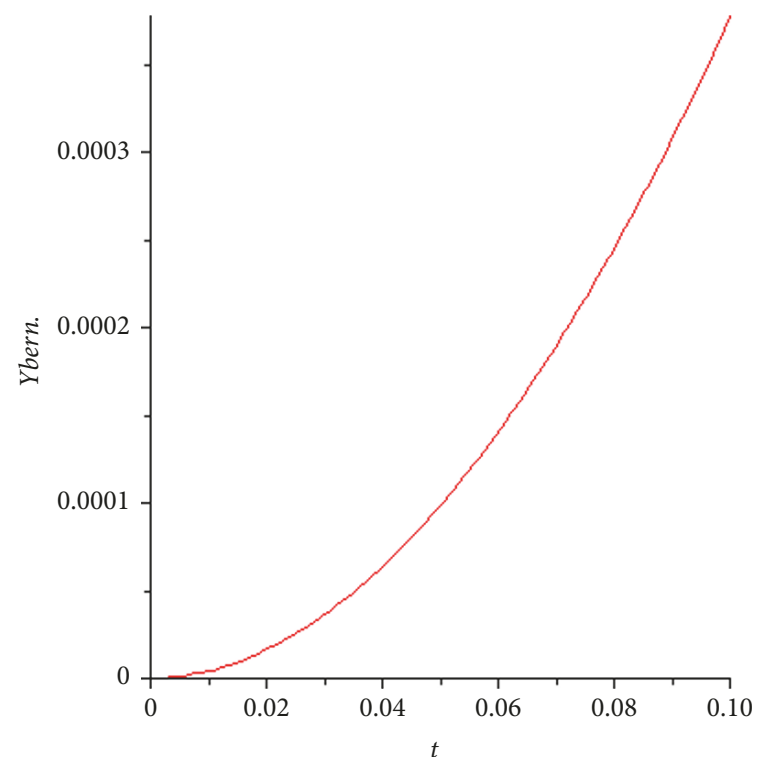

(a)

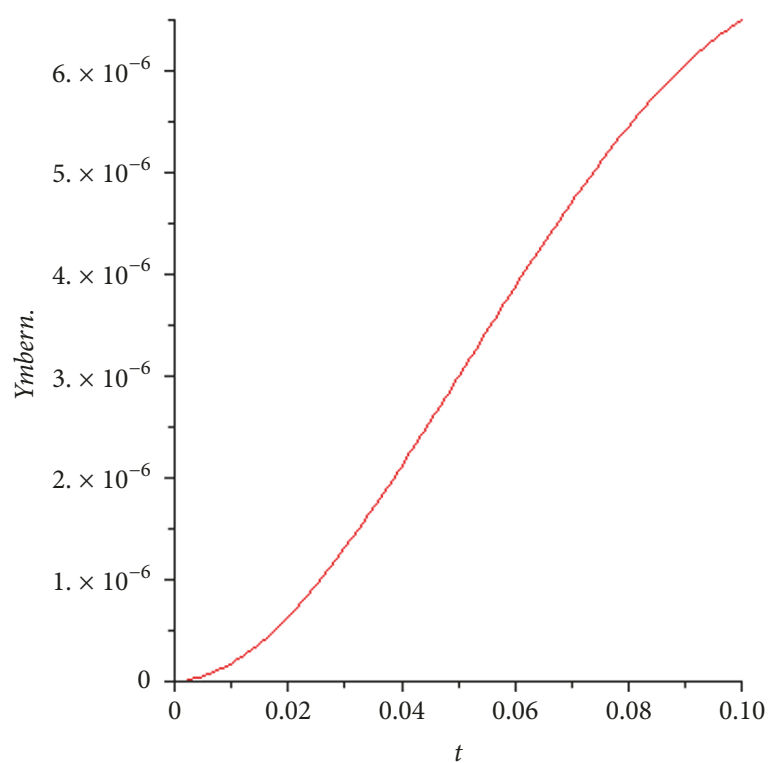

(b)

Figure 3: The absolute error between ADM with modified Bernstein polynomials and the exact solution when $\mathrm{m}=12$, $\mathrm{v}=8$, and $\mathrm{k}=3$.

The Adomian polynomials for $\mathrm{Ny}$ are

$$
\begin{gathered}
A_{0}=y_{o} \frac{\partial y_{o}}{\partial x}, \\
A_{1}=y_{o} \frac{\partial y_{1}}{\partial x}+y_{1} \frac{\partial y_{o}}{\partial x}, \\
A_{2}=y_{o} \frac{\partial y_{2}}{\partial x}+y_{2} \frac{\partial y_{o}}{\partial x}+y_{1} \frac{\partial y_{1}}{\partial x},
\end{gathered}
$$

Then using (5) the classical Bernstein polynomials of $g(x, t)$ when $\mathrm{v}=\mathrm{m}=6$ is

$$
\begin{aligned}
g_{b}(x, t)= & 2.003859 x t+0.103475 x t^{2}+0.149954 x t^{3} \\
& -0.27935 x t^{4}+\cdots,
\end{aligned}
$$

and modified Bernstein polynomials (21) of $g(x, t)$ with $\mathrm{k}=2$ are

$$
\begin{aligned}
g_{m b}(x, t)= & 1.986611 x t+0.045744 x t^{2} \\
& +0.504281 x t^{3}-0.25375 x t^{4}+\cdots .
\end{aligned}
$$

By (22) with $v=1$, we have

$$
\begin{aligned}
y_{0} & =L^{-1}\left(g_{m b}(x, t)\right)+y(x, 0)=0.993306 x t^{2} \\
& +0.015248 x t^{3}+0.12607 x t^{4}-0.050750 x t^{5} \ldots, \\
y_{1} & =-L^{-1}\left(-v \frac{\partial^{2} y_{0}}{\partial x^{2}}\right)-L^{-1}\left(A_{0}\right)=-0.197331 x t^{5} \\
& -0.005049 x t^{6}-0.035812 x t^{7}+0.012122 x t^{8} \\
& +\cdots,
\end{aligned}
$$

$$
\begin{aligned}
y_{2} & =-L^{-1}\left(-v \frac{\partial^{2} y_{1}}{\partial x^{2}}\right)-L^{-1}\left(A_{1}\right)=0.049003 x t^{8} \\
& +0.001783 x t^{9}+0.012105 x t^{10}-0.003795 x t^{11} \\
& +\cdots
\end{aligned}
$$

And we obtain

$$
\begin{aligned}
y_{m b}(x, t)= & \sum_{i=0}^{6} y_{i} \\
= & 0.993306 x t^{2}+0.015248 x t^{3} \\
& +0.126070 x t^{4}-0.248081 x t^{5} \\
& -0.083749 x t^{6}+\cdots,
\end{aligned}
$$

The absolute error of $y_{m b}(x, t)$ and $y_{b}(x, t)$ is presented in Table 4 and Figure 4 with the exact solution $y(x, t)=$ $x \sin \left(t^{2}\right)$.

Also Figure 4 presents the absolute error of ADM with Bernstein polynomial in (a) and ADM with modified Bernstein polynomial in (c) at $\mathrm{m}=\mathrm{v}=6$ and $\mathrm{k}=2$. The absolute errors generated using the ADM with Bernstein polynomial are of $10^{-3}$ while the errors yielded from ADM with modified Bernstein polynomial are of $10^{-4}$.

\section{Conclusions}

In this paper, we show that utilizing modified Bernstein polynomials is smartly thought to modify the performance 
TABLE 4: Comparison of absolute errors using $y_{6}$ when $\mathrm{m}=\mathrm{v}=6, \mathrm{k}=2$, and $\mathrm{x}=0.1$.

\begin{tabular}{lrr}
\hline$t$ & $\left|y_{\text {exact }}-y_{b}\right|$ & $\left|y_{\text {exact }}-y_{\text {mb }}\right|$ \\
\hline 0 & 0 & 0 \\
\hline 0.1 & $5.512102 \mathrm{E}-6$ & $4.149093 \mathrm{E}-6$ \\
\hline 0.2 & $3.401160 \mathrm{E}-5$ & $1.849504 \mathrm{E}-6$ \\
\hline 0.3 & $8.851342 \mathrm{E}-5$ & $2.838128 \mathrm{E}-5$ \\
\hline 0.4 & $1.404426 \mathrm{E}-5$ & $9.121566 \mathrm{E}-5$ \\
\hline 0.5 & $1.256008 \mathrm{E}-4$ & $1.620426 \mathrm{E}-4$ \\
\hline 0.6 & $4.250973 \mathrm{E}-5$ & $1.880417 \mathrm{E}-4$ \\
\hline 0.7 & $4.360788 \mathrm{E}-4$ & $1.086168 \mathrm{E}-4$ \\
\hline 0.8 & $1.050197 \mathrm{E}-3$ & $1.020235 \mathrm{E}-4$ \\
\hline 0.9 & $1.718854 \mathrm{E}-3$ & $3.752218 \mathrm{E}-4$ \\
\hline 1 & $2.024768 \mathrm{E}-3$ & $4.863297 \mathrm{E}-4$ \\
\hline MSE & $8.393551358 \mathrm{E}-7$ & $4.702782622 \mathrm{E}-8$ \\
\hline
\end{tabular}

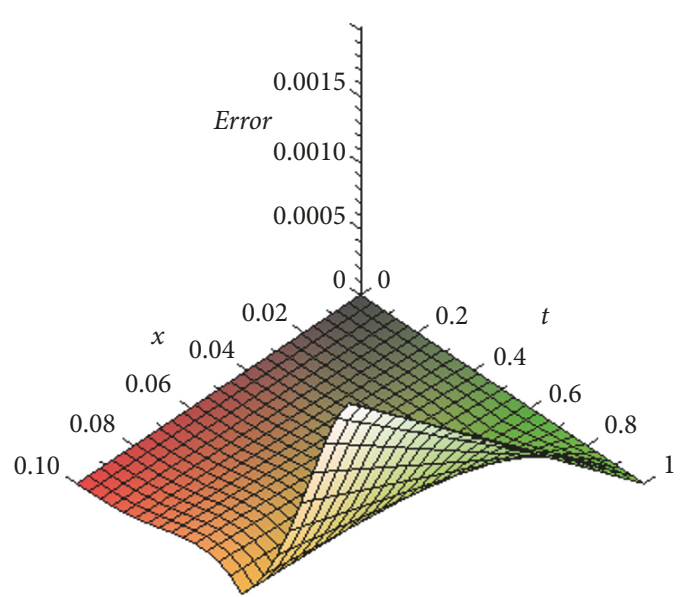

(a) The absolute error for classical Bernstein polynomials

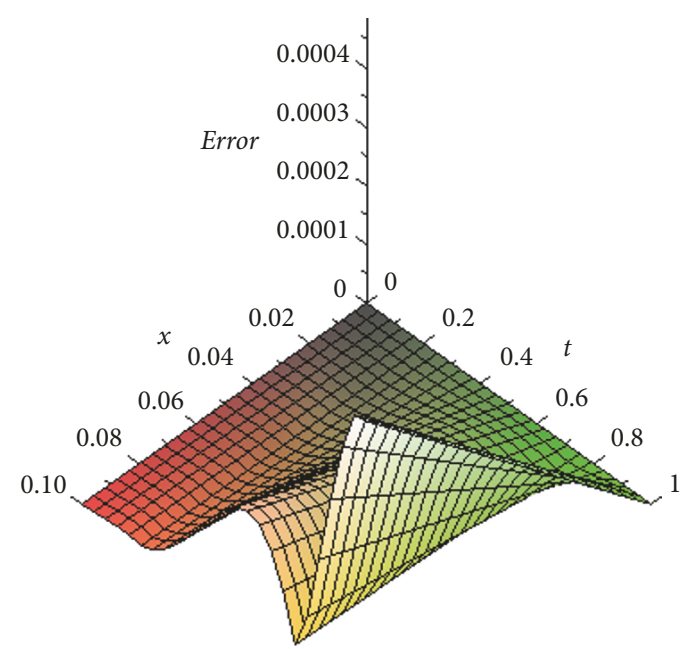

(c) The absolute error for modified Bernstein polynomials

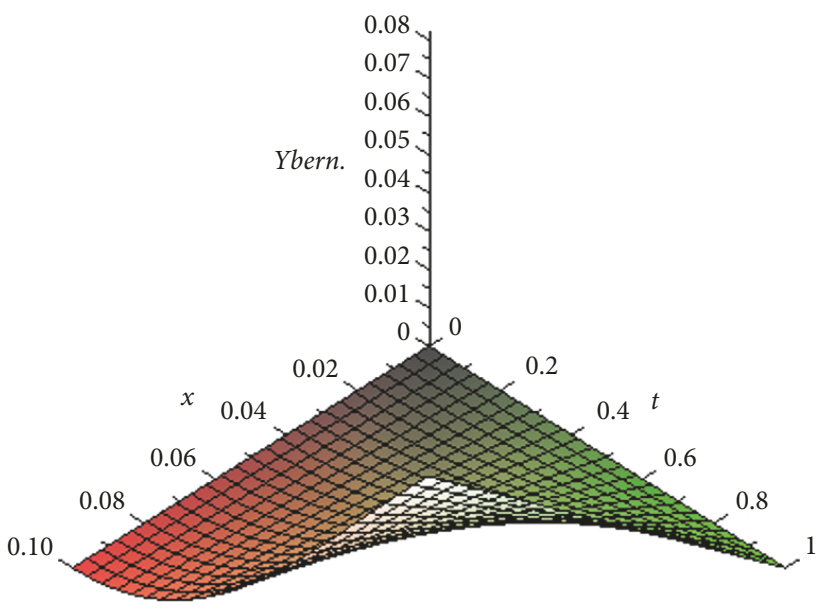

(b) The numerical solution for classical Bernstein polynomials

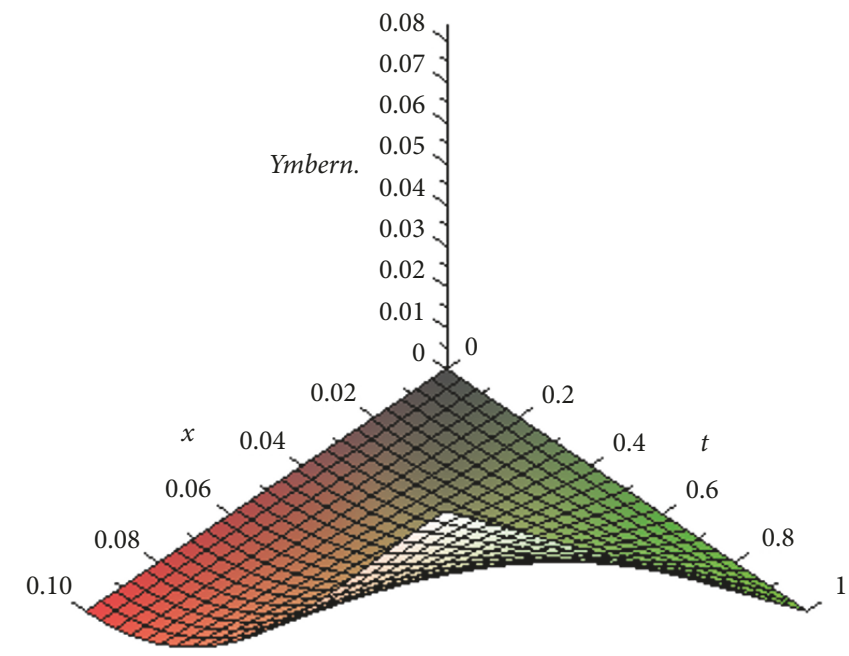

(d) The numerical solution for modified Bernstein polynomials

FIGURE 4: The absolute error between ADM with classical and modified Bernstein polynomials and the exact solution using $y_{6}$ when $\mathrm{m}=\mathrm{v}=6$, $\mathrm{k}=2$, and $\mathrm{x}=0.1$. 
of the Adomian decomposition technique. The fundamental preferred standpoint of this strategy is that it can be used specifically for all sort of differential and integral equations.

We utilize modified Bernstein extensions of the nonlinear term to get more exact outcomes. Figures empower us to consider the difference between utilizing two strategies graphically. Tables are additionally given to demonstrate the variety of the outright mistakes for bigger estimation, to be specific for bigger $\mathrm{m}$. We observed from the numerical outcomes in Tables 1-4 and Figures 1-4 that the ADM with modification Bernstein polynomials gives more exact and robust numerical solution than the classical Bernstein polynomials. Every one of the calculations was done with the guide of Maple 13 programming.

\section{Data Availability}

The data used to support the findings of this study are available from the corresponding author upon request.

\section{Conflicts of Interest}

The authors declare that there are no conflicts of interest regarding the publication of this paper.

\section{Acknowledgments}

The research is supported by College of Computer Sciences and Mathematics, University of Mosul, Republic of Iraq, under Project no. 11251357.

\section{References}

[1] S. Muhammad and I. Muhammad, "Some multi-step iterative methods for solving nonlinear equations," Open Journal of Mathematical Sciences, vol. 1, no. 1, pp. 25-33, 2017.

[2] Y. Yang and L. Hua, "Variational iteration transform method for fractional differential equations with local fractional derivative," Abstract and Applied Analysis, vol. 2014, Article ID 760957, 9 pages, 2014.

[3] U. R. Hamood, S. S. Muhammad, and A. Ayesha, "Combination of homotopy perturbation method (HPM) and double sumudu transform to solve fractional KDV equations," Open Journal of Mathematical Sciences, vol. 2, no. 1, pp. 29-38, 2018.

[4] A. M. Wazwaz, "Construction of solitary wave solutions and rational solutions for the KdV equation by Adomian decomposition method," Chaos, Solitons \& Fractals, vol. 12, no. 12, pp. 2283-2293, 2001.

[5] N. Bildik and A. Konuralp, "The use of variational iteration method, differential transform method and Adomian decomposition method for solving different types of nonlinear partial differential equations," International Journal of Nonlinear Sciences and Numerical Simulation, vol. 7, no. 1, pp. 65-70, 2006.

[6] T. Madeeha, N. N. Muhammad, S. Rabia, V. Dumitru, I. Muhammad, and S. Naeem, "On unsteady flow of a viscoelastic fluid through rotating cylinders," Open Physics, vol. 1, no. 1, pp. $1-15,2017$.

[7] A. Sannia, Q. Haitao, A. Muhammad, J. Maria, and I. Muhammad, "Exact solutions of fractional Maxwell fluid between two cylinders," Open Journal of Mathematical Sciences, vol. 1, no. 1, pp. 52-61, 2017.

[8] Q. Haitao, F. Nida, W. Hassan, and S. Junaid, "Analytical solution for the flow of a generalized Oldroyd-B fluid in a circular cylinder," Open Journal of Mathematical Sciences, vol. 1, no. 1, pp. 85-96, 2017.

[9] M. M. Hosseini, "Adomian decomposition method with Chebyshev polynomials," Applied Mathematics and Computation, vol. 175, no. 2, pp. 1685-1693, 2006.

[10] N. Bildik and Deniz, "Modified Adomian decomposition method for solving Riccati differential equations," Review of the Air Force Academy, vol. 3, no. 30, pp. 21-26, 2015.

[11] Y. Liu, "Adomian decomposition method with orthogonal polynomials: Legendre polynomials," Mathematical and Computer Modelling, vol. 49, no. 5-6, pp. 1268-1273, 2009.

[12] Y. Mahmoudi et al., "Adomian decomposition method with Laguerre polynomials for solving ordinary differential equation," Journal of Basic and Applied Scientific Research, vol. 2, no. 12, pp. 12236-12241, 2012.

[13] D. Rani and V. Mishra, "Approximate solution of boundary value problem with bernstein polynomial laplace decomposition method," International Journal of Pure and Applied Mathematics, vol. 114, no. 4, pp. 823-833, 2017.

[14] G. G. Lorentz, Bernstein Polynomials, Chelsea Publishing Series, 1986.

[15] J. Cicho and Z. Goi, "On Bernoulli sums and Bernstein polynomials," Discrete Mathematics and Theoretical Computer Science, pp. 1-12, 2009.

[16] G. Adomian, Nonlinear Stochastic Operator Equations, Academic Press, San Diego, CA, USA, 1986. 


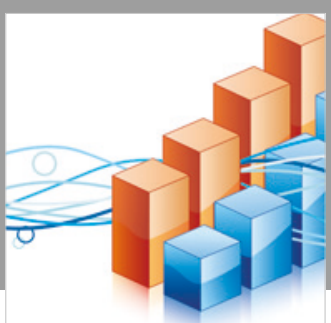

Advances in

Operations Research

\section{-n-m}
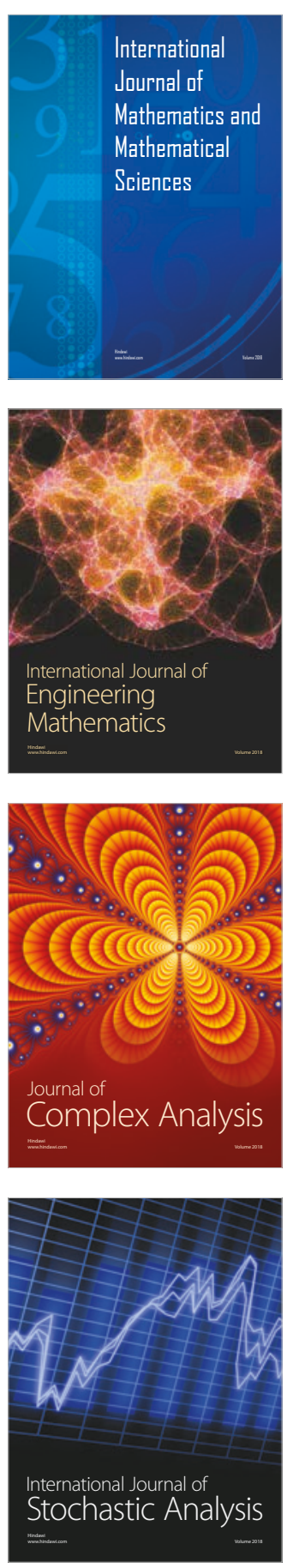
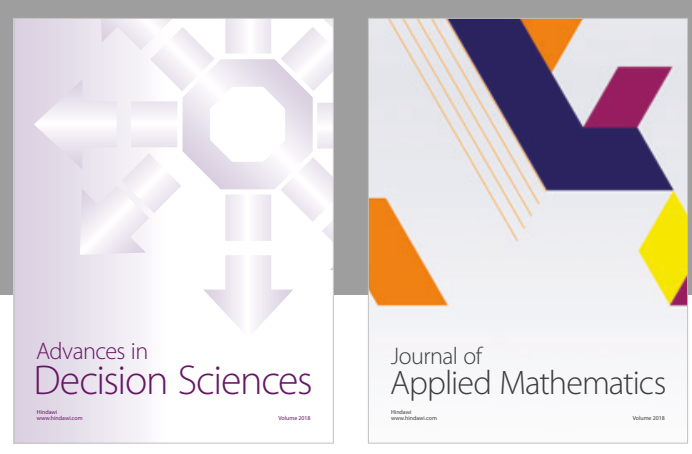

Journal of

Applied Mathematics
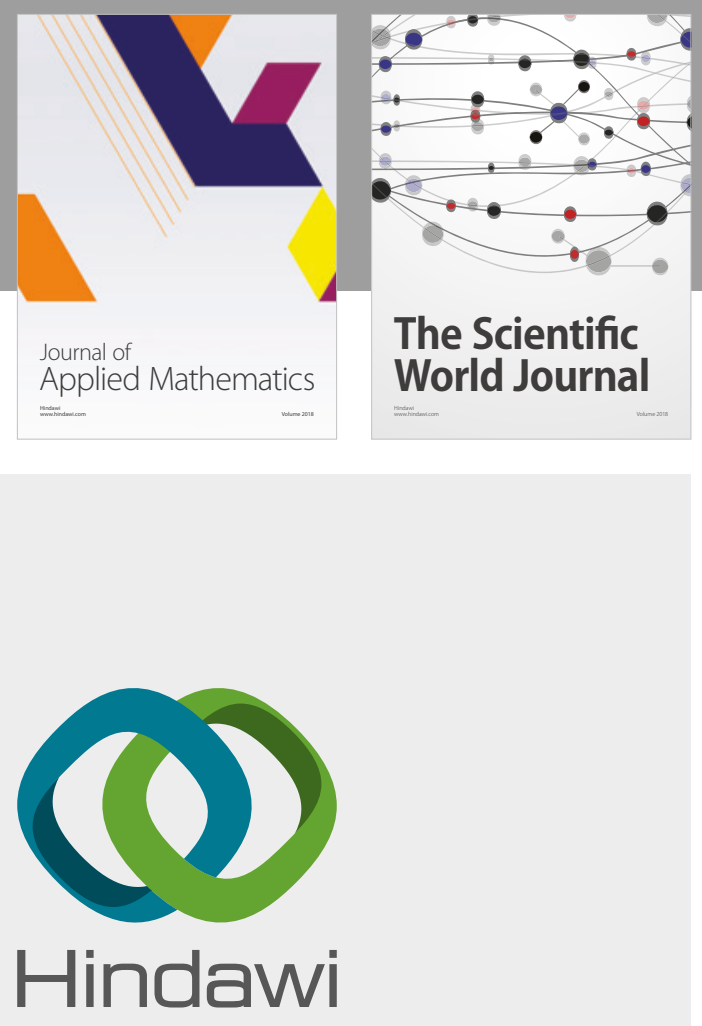

Submit your manuscripts at

www.hindawi.com

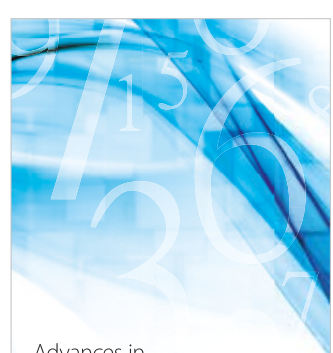

Advances in
Numerical Analysis
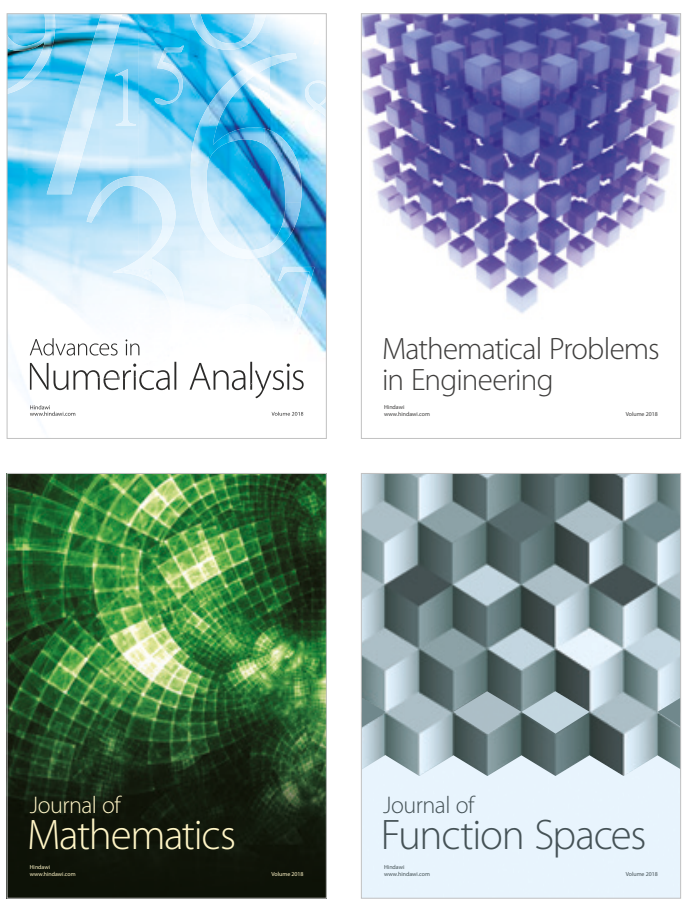

Mathematical Problems in Engineering

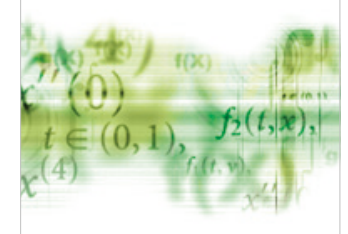

International Journal of

Differential Equations

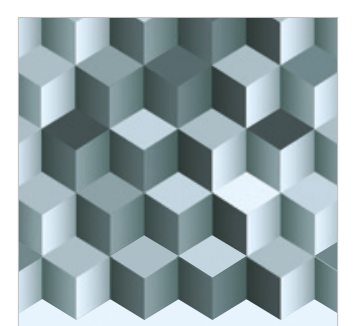

Journal of

Function Spaces

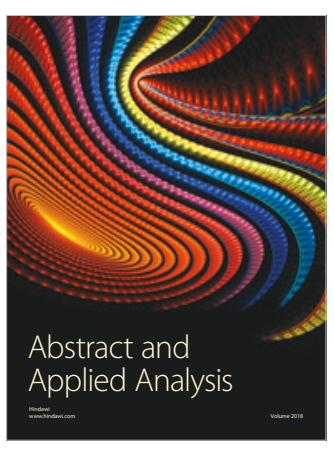

The Scientific

World Journal

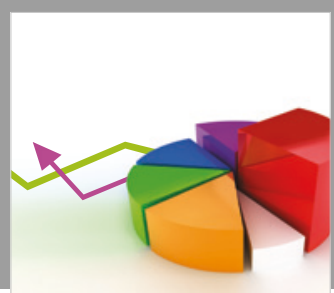

Journal of

Probability and Statistics
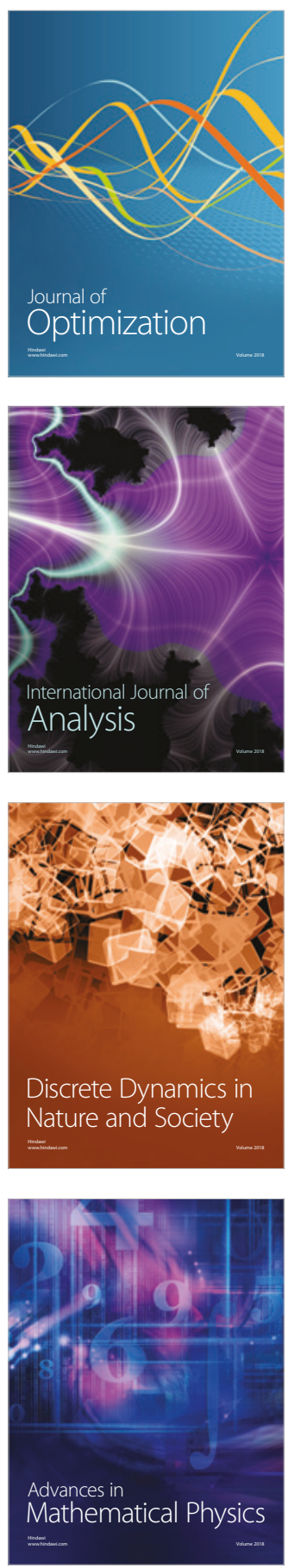